\title{
A Framework for the V\&V Capability Assessment Focused on the Safety-Criticality
}

\author{
Kyung-A Yoon* Seung-Hun Park Doo-Hwan Bae \\ Div. of Computer Science, EECS \\ Korea Advanced Institute of Science and Technology \\ \{kayoon, shpark,bae\}@se.kaist.ac.kr \\ Hoon-Seon Chang Jae-Cheon Jung \\ Plant Engineering and Construction Div. \\ Korea Power Engineering Company Inc. \\ $\{j$ jjung, hschang\}@kopec.co.kr
}

\begin{abstract}
As the importance of verification and validation $(V \& V)$ activities is growing, the necessity of criticality-based assessment framework of $V \& V$ capability is increasing in the safety-critical software organizations. Although several maturity models for quality improvement, such as Capability Maturity Model Integration (CMMI) and Testing Maturity Model (TMM), were developed following the industry's request, they have the limitation to support enough V\&V assessment for the safety-critical software. In this paper, we propose the framework of $V \& V$ capability assessment in order to assist in performing "safety-criticality" assessment. To provide the essential V\&V practices and the confidential capability level scheme, our framework has five $V \& V$ capability levels based on the integrity level scheme of IEEE Std.1012 and the V\&V tasks that come from IEEE Std.1012, 7-4.3.2, 1228, RG 1.168, and CMMI.
\end{abstract}

\section{Introduction}

In the safety-critical systems such as Nuclear Power Plant(NPP) systems, the very high confidence for software quality is required because those systems have high catastrophic potential and relatively low-cost alternatives [1]. Recently, the concept of software V\&V is accepted as a way to assure the quality of the new digitalized safety-critical system. As the importance of

${ }^{*}$ This work was supported by the Ministry of Information \& Communication, Korea, under the Information Technology Research Center(ITRC) Support Program.
$\mathrm{V} \& \mathrm{~V}$ activities is growing, the necessity of criticalitybased assessment framework of V\&V capability is increasing in the safety-critical software organizations since they want to select the internal/external supplier which has enough V\&V capability to develop safetycritical software. Several maturity models for quality and productivity improvement are developed following the industry's request. CMMI [2] is organized with five maturity levels and Process Area(PA)s to support process improvement. Although CMMI provides the $\mathrm{V} \& \mathrm{~V}$ practices in its two PAs, which are the Verification and Validation, it does not sufficiently address the $\mathrm{V} \& \mathrm{~V}$ process. Therefore, TMM [3, 13] was developed to assess and improve a testing process. However, TMM does not focus on the safety-criticality since its target is general software $\mathrm{V} \& \mathrm{~V}$ organization.

In this paper, we propose the framework of $\mathrm{V} \& \mathrm{~V}$ capability assessment focused on the safety-criticality in order to assist in performing safety-criticality assessment. The software integrity level and the minimum set of V\&V tasks of IEEE Std.1012 ${ }^{1}$ [4] are used as the basis of our $V \& V$ assessment model and questionnaire. In addition, $\mathrm{V} \& \mathrm{~V}$ tasks which are recommended by IEEE Std.7-4.3.2 [5, 6], 1228 [7] and RG 1.168 [8] are included to make our framework reflect the safety-critical software domain. To complement our model, we add some V\&V tasks that are identified by the mapping results between our V\&V tasks and CMMI PAs, and ISO 9001 [9].

The remainder of this paper is organized as follows. Section 2 briefly explains CMMI, ISO 9001, TMM and

\footnotetext{
${ }^{1}$ To save the space, we abbreviate the published year which follows the standard number.
} 
IEEE Std.1012, 7-4.3.2, 1228, and RG 1.168 as background. The development steps, detailed information, and analysis of our framework are described in Section 3 and 4. Finally, we conclude with future work in Section 5 .

\section{Background}

In this section, we illustrate the maturity models and several standards which are referred to develop our framework. The representative process assessment models are CMMI and ISO 9001. CMMI was developed in 1998 by Software Engineering Institute(SEI) of Carnegie Mellon University. It is designed by combining SW-CMM, the Systems Engineering Capability Model(SECM), and the Integrated Product Development(IPD) CMM to support the Software Process Improvement(SPI) activities across the different disciplines in an organization and reduce the cost of performing a training, appraisals, and SPI activities [2]. ISO 9001:2000 specified requirements for a quality management system to assure the quality in design, development, production, installation and servicing. Although these two models are accepted by industry, they don't sufficiently address the software V\&V process [9]. CMMI provides the Verification and Validation PAs in level3. However, they are not enough to provide sufficient visibility into the $\mathrm{V} \& \mathrm{~V}$ capability. To assist software development organizations in evaluating and improving their testing processes, TMM was developed by Illinois Institute of Technology in 1996 [3, 13]. In TMM, "testing" is applied in its broadest sense to encompass all software quality-related activities [3]. As shown in Figure 1, TMM is characterized by five testing maturity levels that can be used in conjunction with the CMMI. However, TMM does not focus on the safetycriticality since its target is a general software V\&V organization. The limitation of TMM with the viewpoint of assessing the criticality-based V\&V capability will be discussed in Section 4.

To develop our assessment framework, the criticality-based assessment framework of V\&V capability, the specific V\&V practices related to safetycritical software are essential components. In order to find these specific practices, we referred to IEEE Std.1012-1998, 7-4.3.2-1993/2003, and 1228-1994, and NRC RG 1.168. IEEE Std.1012-1998, the international standard for software verification and validation, is a process standard that defines the $\mathrm{V} \& \mathrm{~V}$ processes in terms of specific $\mathrm{V} \& \mathrm{~V}$ activities and related tasks [4]. It defines four software integrity levels to describe the criticality of the software, the minimum V\&V tasks to be assigned to each integrity level, and the optional

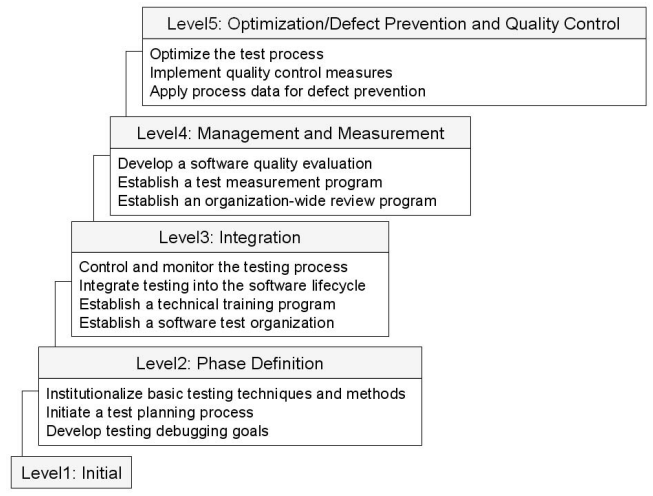

Figure 1. TMM maturity levels and goals

$\mathrm{V} \& \mathrm{~V}$ tasks to allow the user to tailor the $\mathrm{V} \& \mathrm{~V}$ process. The criticality-based software integrity levels denote a range of software criticality values necessary to maintain risks within acceptable limits [4]. According to this standard, software criticality may include safety, security, software complexity, performance, reliability, or other characteristics. In relation to minimum V\&V tasks and software integrity level, IEEE Std.1012 introduces the intensity and rigor applied to V\&V tasks. Higher software integrity levels require the application of greater intensity and rigor to the V\&V tasks. Intensity includes greater scope of analysis across all normal and abnormal system operating conditions and rigor includes more formal techniques and recording procedures. IEEE Std.7-4.3.2-1993, the standard criteria for digital computers in safety systems of nuclear power generating stations, presents tasks to support the specification, design, and implementation of computers in safety systems of nuclear power generating stations. Annex E of this standard describes V\&V tasks throughout life cycle. IEEE Std.1228-1994, the standard for software safety plans, recommends safety-analysis actions in its Annex. The final standard that we referred to is RG 1.168 which developed by U.S.Nuclear Regulatory Commission in 1997. It describes a method of the $\mathrm{V} \& \mathrm{~V}$, reviews, and audits acceptable to the NRC staff for complying with parts of the NRC's regulations for promoting high functional reliability and design quality in software used in safety system.

\section{Framework for the $V \& V$ capability as- sessment focused on the safety-criticality and its development steps}

In this section, we give an explanation on the framework for the $\mathrm{V} \& \mathrm{~V}$ capability assessment focused 
on the safety-criticality and the development steps of its capability model. Figure 2 presents our overall approach.

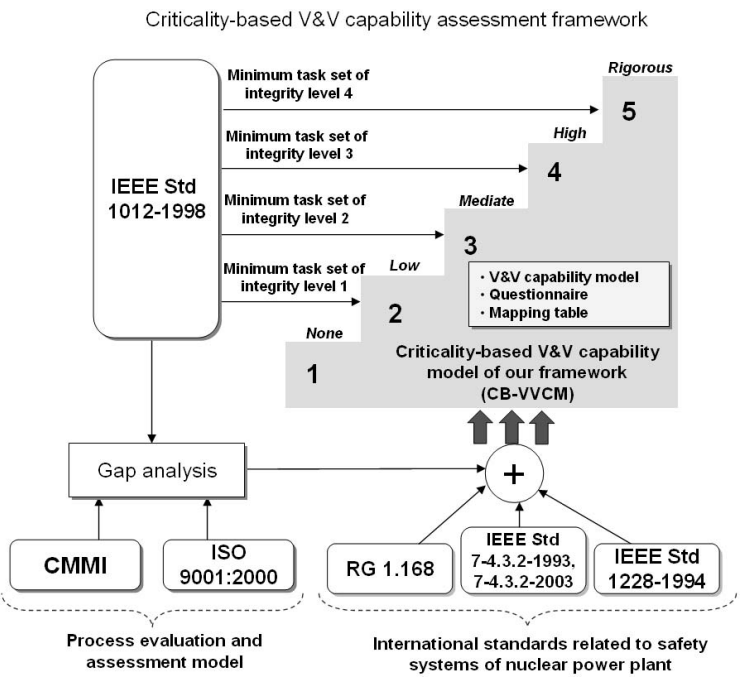

Figure 2. The overall approach

Our framework consists of the Criticality-Based V\&V Capability Model(CB-VVCM), the questionnaire, and the mapping table with other models. The CB-VVCM has five V\&V capability levels based on the integrity level scheme of IEEE Std.1012 and the V\&V tasks that come from IEEE Std.1012, 7-4.3.2, 1228, RG 1.168, and CMMI. The questionnaire is created using the CB-VVCM tasks and the mapping table is the results of mapping the CB-VVCM tasks to the CMMI PAs and the ISO 9001 clauses. The development steps of the CB-VVCM are illustrated in Figure 3.

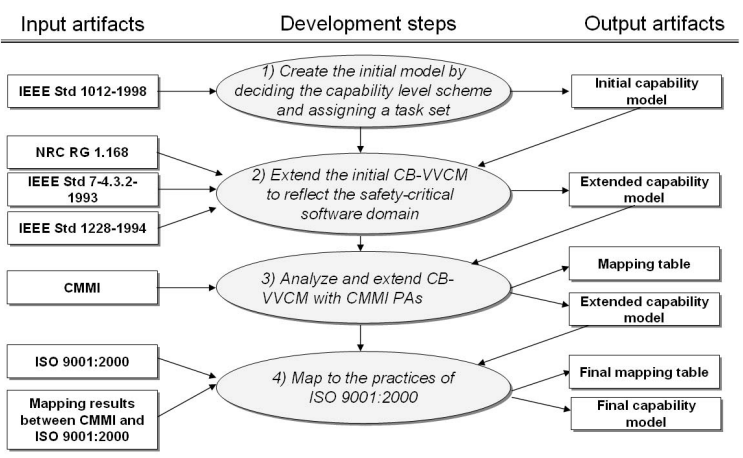

Figure 3. The development steps of the CBVVCM

\subsection{Development steps of the CB-VVCM}

3.1.1. Create the initial model by deciding the capability level scheme and assigning a task set. Deciding the capability level scheme is one of the important things in developing our framework. The capability level should reflect well the software organization's V\&V capability with the view point of "safety-criticality." As we mentioned in section 2, IEEE Std.1012 has the four criticality-based software integrity levels and the minimum V\&V task sets for each of them. Although this integrity level scheme is originally designed to perform the proper $\mathrm{V} \& \mathrm{~V}$ tasks according to the assigned criticality degree of software, it can be used to assess the organization's V\&V capability, too. Because critical, high-integrity software typically requires a larger set and more rigorous and intensive application of $\mathrm{V} \& \mathrm{~V}$ tasks, the software organization which can observe the minimum $V \& V$ tasks of the high integrity level has the high criticality-based V\&V capability. Therefore, the criticality-based V\&V capability level of an organization is decided by assessing whether the organization performs its defined minimum $\mathrm{V} \& \mathrm{~V}$ tasks or not. The relation between the software integrity levels of IEEE Std.1012 and our V\&V capability levels is presented in Figure 2. Table 1 summarizes the objective of each criticality-based V\&V capability level of CB-VVCM. After deciding the scheme of capability level and assigning the minimum task sets for each level, the initial CB-VVCM is created.

3.1.2. Extend the initial CB-VVCM to reflect the safety-critical software domain. The part of optional $\mathrm{V} \& \mathrm{~V}$ tasks in IEEE Std.1012 which can support the safety-critical software $V \& V$ is not included to the minimum $\mathrm{V} \& \mathrm{~V}$ tasks because the application target of IEEE Std.1012 is general software systems. Since the initial CB-VVCM has the same minimum V\&V tasks set of IEEE Std.1012-1998, it should be strengthened by adding particular V\&V tasks for the safety-critical software. To complement CB-VVCM, we consider the following standards which contain the safety-critical specific V\&V tasks: IEEE Std.7-4.3.2, 1228, and RG 1.168. All V\&V tasks which are recommended from these standards are part of the minimum V\&V tasks and the optional V\&V tasks of IEEE Std.1012. Except five optional $V \& V$ tasks, $V \& V$ tasks of IEEE Std.74.3.2 are covered in the minimum $V \& V$ tasks of IEEE Std.1012. We choose these tasks as the V\&V tasks of our model. RG 1.168 mentions six tasks in the optional V\&V tasks of IEEE Std.1012-1986 for the safetycritical software V\&V in NPP. At the revision from the IEEE Std.1012-1986 to the IEEE Std.1012-1998, "Con- 
Table 1. The objective of each criticality-based V\&V capability level in CB-VVCM

\begin{tabular}{|l|l|}
\hline Level & Objectives \\
\hline Rigorous & $\begin{array}{l}\text { - Prevent the critical software system failure that } \\
\text {. Directly affects the loss of life } \\
\text { - Does not permit that any mitigation strategies is im- } \\
\text { plemented }\end{array}$ \\
\hline 4 & $\begin{array}{l}\text { - Prevent the software system failure that } \\
\text { - Directly affects the major and permanent injury } \\
\text { - Affects important system performance } \\
\text { - Permit that workaround strategies can be im- } \\
\text { plemented to compensate completely for loss of } \\
\text { performance }\end{array}$ \\
\hline 3 & $\begin{array}{l}\text { - Prevent the software system failure that } \\
\text { - Directly affects the minor injury or illness } \\
\text { - Affects system performance } \\
\text { - Permit that workaround strategies can be imple- } \\
\text { mented to compensate partially for loss of perfor- } \\
\text { mance }\end{array}$ \\
\hline $\begin{array}{l}\text { mow } \\
\text { - Prevent the software system failure that } \\
\text {. Creates inconvenience to the user if the function does } \\
\text { not perform in accordance with requirements } \\
\text {. Gives noticeable effect on system performance }\end{array}$ \\
\hline 1 \\
None
\end{tabular}

figuration management" and "Installation and checkout testing" tasks are included in the minimum V\&V tasks from the optional V\&V tasks. As the result, we take four tasks from RG 1.168 for our CB-VVCM. In IEEE Std.1228, we find three V\&V tasks related to the safety analysis which are overlapped the optional V\&V tasks of IEEE Std.1012. Table 2 shows the result of CB-VVCM extension by adding V\&V tasks for safetycritical software of NPP. The added V\&V tasks are assigned to levels 4 and 5 by considering in terms of rigorousness, intensiveness, and fundamentalness.

After deciding the $\mathrm{V} \& \mathrm{~V}$ tasks which reflect the safety-critical software domain, we construct the structure of our CB-VVCM as shown in Figure 4.

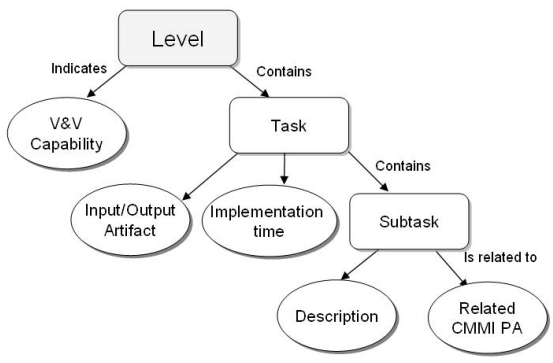
Figure 4 . The structure of criticality-based V\&V
capability model
Table 2. The V\&V tasks which are used for the CB-VVCM extension

\begin{tabular}{|l|l|l|}
\hline Level & V\&V tasks & Sources \\
\hline 5 & $\begin{array}{l}\text { Evaluation of user doc- } \\
\text { ument }\end{array}$ & RG 1.168 \\
\cline { 2 - 3 } & $\begin{array}{l}\text { Regression analysis and } \\
\text { testing }\end{array}$ & $\begin{array}{l}\text { RG 1.168, IEEE } \\
\text { Std.1228 }\end{array}$ \\
\cline { 2 - 3 } & Test evaluation & $\begin{array}{l}\text { RG 1.168, IEEE } \\
\text { Std.1228 }\end{array}$ \\
\cline { 2 - 3 } & $\begin{array}{l}\text { Sizing and timing anal- } \\
\text { ysis }\end{array}$ & IEEE Std.1228 \\
\cline { 2 - 3 } & Database analysis & IEEE Std.7-4.3.2 \\
\hline 4 & Audits & RG 1.168 \\
\cline { 2 - 3 } & Inspection & IEEE Std.7-4.3.2 \\
\cline { 2 - 3 } & Algorithm analysis & IEEE Std.7-4.3.2 \\
\cline { 2 - 3 } & Control flow analysis & IEEE Std.7-4.3.2 \\
\cline { 2 - 3 } & Data flow analysis & IEEE Std.7-4.3.2 \\
\hline
\end{tabular}

It consists of the level, task, subtasks and other constituents such as input/output artifacts and implementation time. The "Implementation time" means the specific lifecycle phase when the task is performed. The "Related CMMI PA" presents the overlapped CMMI PAs related to the specific V\&V tasks of CB-VVCM to support the parallel assessment effort with CMMI.

\subsubsection{Analyze and extend CB-VVCM with CMMI} PAs. We have two purposes in mapping CB-VVCM tasks to CMMI PAs. The first is the creation of the mapping table which can be used in conjunction with CMMI to assess both the general software process and the $\mathrm{V} \& \mathrm{~V}$ process. The second is the derivation of additional V\&V tasks from CMMI PAs to complement our model by analyzing the mapping result. Since CMMI PAs and our V\&V task set differ in the format and detail-level of describing, we compare the subtasks of each our V\&V task with practices of each CMMI PA. The mapping conditions are whether a subtask of our model and a practice of CMMI PA have (1)the similar purpose or contents and (2)the overlapped artifacts. To check the second condition, we compare the input/output artifacts that are described in IEEE Std.1012 and the direct/indirect artifacts of Practice Implementation Indicator Descriptions(PIIDs) that were used in SEI's pilot sites [10]. For example, Table 3 presents the mapping results of "3.1 Baseline change assessment" $\mathrm{V} \& \mathrm{~V}$ task in level 3. Most comparison results are partial mapping with the CMMI PA viewpoint. In other words, one $\mathrm{V} \& \mathrm{~V}$ task of our model can be mapped to no CMMI practice or partial CMMI practices of one or more PAs. It is natural because the target of CMMI is general software process and its scope is broader than 
that of ours.

Table 3. The example of comparison result : 3.1 Baseline change assessment

\begin{tabular}{|c|c|c|c|c|c|c|}
\hline \multicolumn{4}{|c|}{ CB-VVCM } & \multicolumn{3}{|c|}{ CMMI } \\
\hline \multirow{2}{*}{ Task } & \multirow{2}{*}{ Subtask } & \multicolumn{2}{|c|}{ Artifact } & \multirow{2}{*}{$\begin{array}{l}\text { PA and } \\
\text { Practice }\end{array}$} & \multicolumn{2}{|r|}{ PIIDs } \\
\hline & & Input & Output & & Direct & Indirect \\
\hline \multirow[t]{3}{*}{$\begin{array}{l}\text { Baseline } \\
\text { change } \\
\text { assessm- } \\
\text { ent }\end{array}$} & $\begin{array}{l}\text { Evaluate proposed } \\
\text { software changes } \\
\text { for effects on } \\
\text { previously } \\
\text { completed V\&V } \\
\text { tasks }\end{array}$ & $\begin{array}{l}\cdot \text {-sVVP* } \\
\text {-Proposed } \\
\text { changes } \\
\text {-Hazard } \\
\text { analysis } \\
\text { report } \\
\text {-Risks } \\
\text { identified } \\
\text { by v8V } \\
\text { tasks }\end{array}$ & $\begin{array}{l}\text { - Udatat } \\
\text { sVVV tasks: } \\
\text { Baseline } \\
\text { change } \\
\text { assessment } \\
\text {-Anomaly } \\
\text { report }\end{array}$ & $\begin{array}{l}\text { Configuration } \\
\text { management } \\
\text { SP2.1 }\end{array}$ & \begin{tabular}{|l} 
- Change \\
request
\end{tabular} & \begin{tabular}{|l} 
- Change request \\
impact analysis \\
-Change request \\
lifecycle or \\
workfliow \\
description \\
-ccB/stakeholder \\
review records \\
- Configuration item \\
revision history
\end{tabular} \\
\hline & $\begin{array}{l}\text { Plan iteration of } \\
\text { affected tasks or } \\
\text { initiate new tasks } \\
\text { to address } \\
\text { software baseline } \\
\text { changes or } \\
\text { iterative } \\
\text { development } \\
\text { processes }\end{array}$ & $\begin{array}{l}\text {-sVVP } \\
\text {-Proposed } \\
\text { changes } \\
\text {-Hazard } \\
\text { analysis } \\
\text { report }\end{array}$ & $\begin{array}{l}\text {-Update } \\
\text { SVVP tasks: } \\
\text { Baseline } \\
\text { change } \\
\text { assessment } \\
\text {-Anomaly } \\
\text { report }\end{array}$ & $\begin{array}{l}\text { Project } \\
\text { Planning } \\
\text { SP 2.1 }\end{array}$ & $\begin{array}{l}\text { Project } \\
\text { schedules } \\
\text {-Schedule } \\
\text { dependenc } \\
\text { ies } \\
\text { - Project } \\
\text { budget }\end{array}$ & \begin{tabular}{|l|} 
Stafting profile \\
-Identified major \\
mile stones \\
- Task \\
dependencies \\
\end{tabular} \\
\hline & & & & & & \\
\hline
\end{tabular}

Figure 5 describes the characteristics of the whole result using Venn diagram. In the CB-VVCM side, the non-overlapped $\mathrm{V} \& \mathrm{~V}$ tasks are mainly the operation and maintenance related V\&V tasks. In order to identify the complement point from this result, we should focus on the other side, CMMI. The non-overlapped CMMI PAs are four PAs: OID, QPM, OT, and OEI as shown in Figure 5. These four PAs are related to organizational process management and improvement.

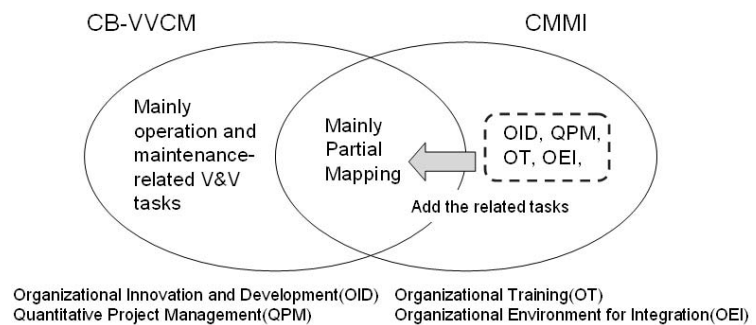

\section{Figure 5. The characteristics of comparison re-} sult between CB-VVCM and CMMI

This result means that organizational and managerial $\mathrm{V} \& \mathrm{~V}$ practices should be completed to make CBVVCM more useful since CB-VVCM V\&V tasks put much focus on technical practices. By referring the practices of OID, QPM, OT, and OEI, we derived four organizational level V\&V tasks and then extended CBVVCM like Table 4. The four tasks were assigned from level 2 to level 4 by considering its original CMMI level and the other V\&V tasks in each capability level.

3.1.4. Map to the practices of ISO 9001:2000. In addition to CMMI, we mapped CB-VVCM to ISO 9001 to support to parallel assessment and find the complement point. However, it is too difficult to compare because the clauses of ISO 9001 are described conceptu-
Table 4. The V\&V tasks which are derived from the non-overlapped PAs of CMMI

\begin{tabular}{|l|l|l|}
\hline Level & V\&V tasks & $\begin{array}{l}\text { Source } \\
\text { (level) }\end{array}$ \\
\hline 4 & $\begin{array}{l}\text { Evaluating and improving V\&V } \\
\text { process }\end{array}$ & OID (5) \\
\cline { 2 - 3 } & $\begin{array}{l}\text { Quantitative management review of } \\
\text { V\&V }\end{array}$ & QPM (4) \\
\hline 3 & $\begin{array}{l}\text { Establishing organizational policy } \\
\text { and committee for guaranteeing in- } \\
\text { dependent V\&V }\end{array}$ & $\begin{array}{l}\text { OEI (3) } \\
\text { (IEEE } \\
\text { Std.7-4.3.2) }\end{array}$ \\
\hline 2 & $\begin{array}{l}\text { Establishing managerial and techni- } \\
\text { cal V\&V training program }\end{array}$ & OT (3) \\
\hline
\end{tabular}

ally and contain few V\&V issues. Therefore, we performed the initial comparison between CB-VVCM and ISO 9001 with the mapping result between CB-VVCM and CMMI of the previous step and the mapping result between CMMI and ISO 9001 [11]. And then we aligned and modified the initial result by comparing again the V\&V tasks of CB-VVCM and their initial mapped clauses of ISO 9001 . Table 5 presents the part of comparison result of step 3 and 4 which belongs to level 4. The results of other levels are abbreviated because of space.

\subsection{Criticality-based assessment framework of V\&V capability}

CB-VVCM which is core constituent of our framework and the mapping table with other models were developed according to the development steps of the previous section. CB-VVCM consists of five capability levels and 47 tasks as shown in Figure 6. In addition to Table 5, the mapping table contains the artifact information of CB-VVCM and CMMI to support the assessment at the same time. The questionnaire for the assessment which covers the contents of CB-VVCM is designed as shown in Figure 7 by referring the maturity questionnaire form of CMM [12]. Finally, the ranking policy follows that of CMMI.

\section{Analysis}

In this section, we present the analysis of our framework through the industry's practical viewpoint and the comparison with TMM.

\subsection{Feedback from industry's feasibility study}

The CB-VVCM was reviewed by the Korea Power Engineering Company(KOPEC) which provides the 
Table 5. The part of final mapping table among CB-VVCM, CMMI and ISO 9001 in level 4

\begin{tabular}{|c|c|c|c|}
\hline Level & Task & CMMI & ISO 9001 \\
\hline \multirow[t]{11}{*}{4} & $\begin{array}{l}\text { Interface with } \\
\text { organizational } \\
\text { supporting } \\
\text { processes }\end{array}$ & $\begin{array}{l}\text { OPD SP1.1, IT } \\
\text { SP2.1, REQM } \\
\text { SP1.2, VER SP1.3, } \\
\text { VAL SP1.3 }\end{array}$ & $\begin{array}{lrl}4.1, & 4.2 .1, & 4.2 .2, \\
7.2 .2, & 7.2 .3, & 7.3 .5, \\
7.3 .6, & 7.5 .2, & 8.2 .4, \\
8.3 & \end{array}$ \\
\hline & $\begin{array}{l}\text { Management } \\
\text { and technical } \\
\text { review support }\end{array}$ & $\begin{array}{l}\text { IT SP1.1, REQM } \\
\text { SP1.5, VER SP3.1, } \\
\text { VAL SP2.1 }\end{array}$ & $\begin{array}{l}\text { 7.2.2, 7.3.5, 7.3.6, } \\
7.5 .2,8.2 .4,8.3\end{array}$ \\
\hline & $\begin{array}{l}\text { Quantitative } \\
\text { management } \\
\text { review of V\&V }\end{array}$ & $\begin{array}{l}\text { MA SP1.3, 1.4, 2.1, } \\
2.2,2.3,2.4, \text { QPM } \\
\text { SP1.1, 1.4, 2.1, 2.3, } \\
\text { P2.4 }\end{array}$ & $\begin{array}{l}5.4 .1,7.1,8.1,8.2, \\
8.4,8.5 .1\end{array}$ \\
\hline & $\begin{array}{l}\text { Evaluating } \\
\text { and improving } \\
\mathrm{V} \& \mathrm{~V} \text { process }\end{array}$ & $\begin{array}{l}\text { OID SP1.2, 1.4, 2.1, } \\
2.2,2.3\end{array}$ & 8.5 .1 \\
\hline & Hazard analysis & $\begin{array}{l}\text { TS SP1.1, 2.1, 3.1, } \\
\text { VER SP3.1, VAL } \\
\text { SP2.1 }\end{array}$ & $\begin{array}{l}\text { 7.3.1, 7.3.3, 7.4.1, } \\
\text { 7.5.1, 7.3.5, 7.3.6, } \\
7.5 .2,8.2 .4,8.3\end{array}$ \\
\hline & $\begin{array}{l}\text { Configuration } \\
\text { management } \\
\text { assessment }\end{array}$ & $\begin{array}{l}\text { CM SP3.2, VAL } \\
\text { SP2.1, VER SP3.1 }\end{array}$ & $\begin{array}{lll}4.2 .3, & 4.2 .4, & 7.3 .1, \\
7.3 .7, & 7.3 .5, & 7.3 .6, \\
7.5 .2, & 7.5 .3, & 8.2 .4, \\
8.3 & \end{array}$ \\
\hline & Risk analysis & $\begin{array}{l}\text { RSKM SP2.1, } 2.2 \text {, } \\
3.1, \quad \text { DAR SP1.6, } \\
\text { VER SP3.1, VAL } \\
\text { SP2.1 }\end{array}$ & $\begin{array}{l}\text { 7.3.5, } \\
8.2 .3 .6,\end{array}$ \\
\hline & Audits & VER SP3.1 & $7.3 .5,8.2 .4,8.3$ \\
\hline & Inspection & VER SP3.1 & $7.3 .5,8.2 .4,8.3$ \\
\hline & $\begin{array}{l}\text { Algorithm anal- } \\
\text { ysis }\end{array}$ & VER SP3.1 & $7.3 .5,8.2 .4,8.3$ \\
\hline & \multicolumn{3}{|c|}{ Abbreviated } \\
\hline
\end{tabular}

NPP design engineering and the plant operation and maintenance service. It mainly develops safety-critical systems of NPP through acquisition. Although this company's acquisition process emphasizes on the $\mathrm{V} \& \mathrm{~V}$, the assigned rate of evaluation points to the quality item of Request For Proposals(RFP) is relatively low. To emphasize the importance of the quality concept and promote the efficient assessment of supplier's V\&V capability during acquisition, this company plans to apply our framework to its acquisition process as a tool for assessing supplier's V\&V capability. Before applying, its internal experts reviewed our framework and preliminarily applied it to two finished real projects. The one of projects doesn't have all of the required artifacts of our framework except the project plan, source codes and manuals. On the other hand, the other project provides 46 artifacts such as software verification report(of requirement, design, code), software review report, test procedure, etc. We can easily perform the $\mathrm{V} \& \mathrm{~V}$ capability assessment of this project's supplier through checking whether the recommended artifacts existed in the real artifacts. However, the assessment of the organizational $\mathrm{V} \& \mathrm{~V}$ tasks was impossible because these tasks required the internal information of organization

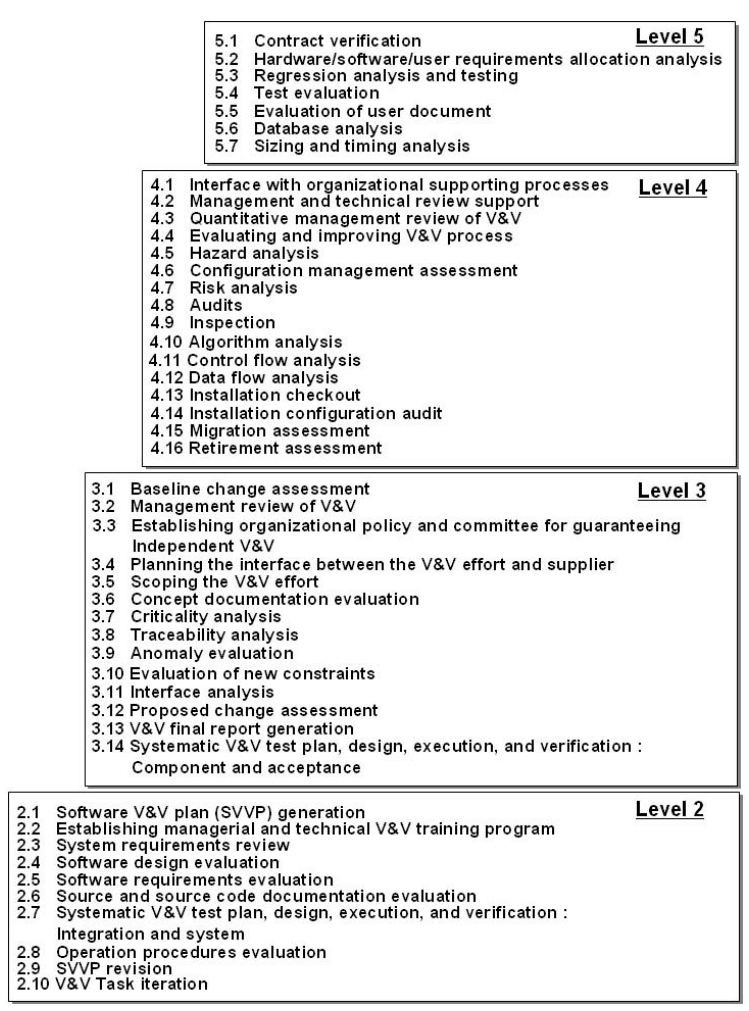

Figure 6. The five levels and tasks of CB-VVCM

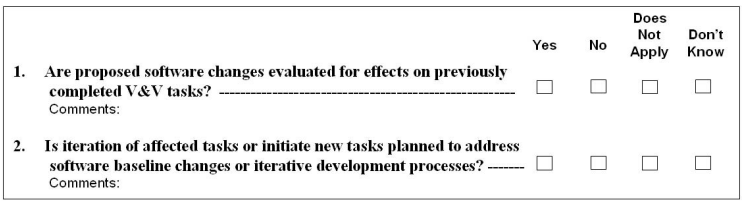

Figure 7. The questionnaire example of our framework

as evidence. Through the expert's review and the feasibility studies, we received the following feedback :

- Since the V\&V tasks and subtasks consist of the specific practices in the field, they are easy to understand during the assessment.

- Since the V\&V tasks provide the specific artifacts, the assessment is easy to perform through checking whether the artifact is produced or not.

- Since an artifact contains the work products of one or more tasks or the terms used in the real artifacts don't always match exactly that of our recommended artifacts, the essential contents and structures of the recommended artifacts should 
be provided to find proper work products as evidence and to assess the specific V\&V task by checking whether the work product found contains the recommended essential contents. For example, in the case of the latter project, its "SOFTWARE REVIEW REPORT/REQUIREMENTS REVIEW XXX PROGRAMMABLE DIGITAL COMPARATORS" document contains the result of some works including traceability analysis and software requirement evaluation.

- The V\&V capability level and the assigned tasks are appropriate to apply in the real industry. However, the granularity of each $\mathrm{V} \& \mathrm{~V}$ tasks should be adjusted.

KOPEC developed a web-based assessment supporting tool based on our framework to use in the acquisition process. Figure 8 shows the screenshot of this tool. By asking supplier candidates to answer questions and upload documents, this company will execute the assessment automatically. The assessor can audit using this system and monitor the result of assessment. For the organizational $\mathrm{V} \& \mathrm{~V}$ tasks, this company has an intention to make the policy that the assessor directly audits the supplier candidate's organizational information within its opening boundary. We recommend that the company which has V\&V capability level 4 or more can be accepted because the rigorous and intensive $\mathrm{V} \& \mathrm{~V}$ tasks are included in level 4 or more.

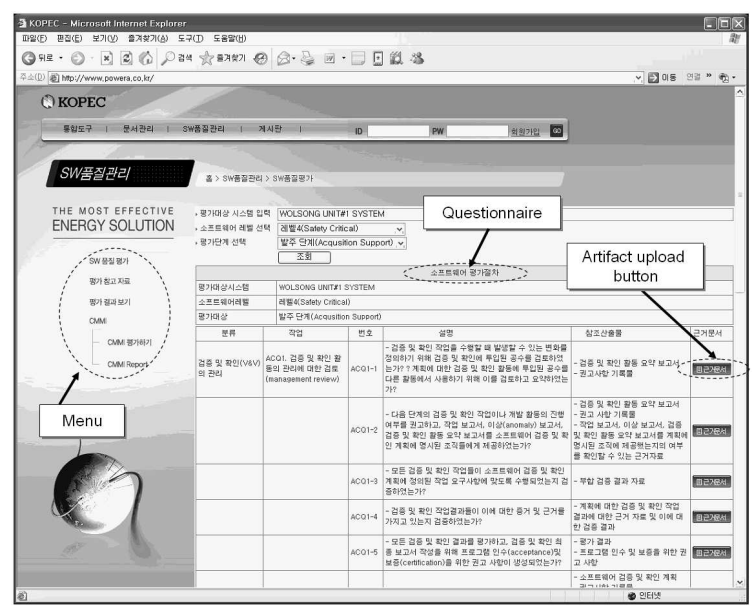

Figure 8. The screenshot of the V\&V capability assessment tool

\subsection{Comparison with TMM}

TMM is one of our related assessment models. We compare our framework with TMM on the following criteria: objective, application scope, structure, supporting parallel assessment with other model, and features. The result is presented in Table 6.

Table 6. The comparison of our framework with TMM

\begin{tabular}{|l|l|l|}
\hline & Our framework & TMM \\
\hline Objective & $\begin{array}{l}\text { Assessment of V\&V } \\
\text { capability of organi- } \\
\text { zation }\end{array}$ & $\begin{array}{l}\text { Assessment and im- } \\
\text { provement of testing } \\
\text { maturity of organi- } \\
\text { zation }\end{array}$ \\
\hline $\begin{array}{l}\text { Application } \\
\text { scope }\end{array}$ & $\begin{array}{l}\text { Safety-critical soft- } \\
\text { ware organization } \\
\text { (internal, external) }\end{array}$ & $\begin{array}{l}\text { General testing or- } \\
\text { ganization (internal) }\end{array}$ \\
\hline Structure & $\begin{array}{l}- \text { Five capability } \\
\text { level } \\
-47 \text { V\&V tasks }\end{array}$ & $\begin{array}{l}\text { - Five maturity level } \\
\text { subgoals goals and 43 }\end{array}$ \\
\hline $\begin{array}{l}\text { Supporting } \\
\text { parallel as- } \\
\text { sessment }\end{array}$ & $\begin{array}{l}\text { CMMI and ISO } \\
\text { 9001 }\end{array}$ & $\begin{array}{l}\text { SW-CMM, CMMI } \\
\text { and ISO 9001 }\end{array}$ \\
\hline Features & $\begin{array}{l}\text { Consisting of } \\
\text { the specific V\&V } \\
\text { practice focusing on } \\
\text { safety-criticality } \\
- \text { Providing the rec- } \\
\text { ommended artifacts } \\
\text { list to support the as- } \\
\text { sessment } \\
- \text { Compliance with } \\
\text { the international } \\
\text { standards }\end{array}$ & $\begin{array}{l}\text { - Providing the spe- } \\
\text { cific assessment pro- } \\
\text { cess } \\
\text { improvement } \\
\text { activities } \\
\text { Reflecting the } \\
\text { industry-wide } \\
\text { software testing } \\
\text { evolution }\end{array}$ \\
\hline
\end{tabular}

Although TMM is widely used in the assessment of testing process, its limitations with the viewpoint of assessing the criticality-based V\&V capability are followings:

- TMM does not provide or emphasize on the safetycritical specific V\&V practices because the target is general software testing organization.

- When the target is the external supplier whose internal information related to the organization is difficult to be opened, the assessment based on TMM is hard to perform. Because the large portion of TMM covers the organizational level tasks, the organizational information is needed as evidence during assessment.

- Since the structured component of TMM such as subgoal, practices etc. does not provide the specific artifact lists which are recommended, the assessment can be difficult to find proper evidences. 
- Since the meaning of "Testing" in TMM is ambiguous, it may not proper to apply $\mathrm{V} \& \mathrm{~V}$ activities except testing activity. According to its guidebook [13], some of its practices in maturity goals mentions specific testing methods such as black/white box test, multilevel test. However, it does not describe any similar methods as safety analysis or criticality analysis for requirement or design.

Consequently, our framework is more appropriate than TMM for assessing the the V\&V capability of safetycritical software organization.

\section{Conclusion and future work}

In this paper, we proposed the framework for $\mathrm{V} \& \mathrm{~V}$ capability assessment focused on the safety-criticality. To provide the essential V\&V practices and the confidential capability level scheme for the $V \& V$ assessment, the criticality-based software integrity level and the minimum V\&V tasks of IEEE Std.1012 are used as the basis. The recommended V\&V tasks of IEEE Std.7-4.3.2, 1228 and RG 1.168 are referenced to reflect the $\mathrm{V} \& \mathrm{~V}$ activities which are emphasized in the safetycritical system. Through mapping our V\&V tasks to the CMMI PAs and ISO 9001 clauses, we found the weak point of our framework and then added the organizational level V\&V tasks to complement it. This mapping table can support to the parallel assessment with CMMI and ISO 9001. Using our framework, the safety-critical software organization which wants to assess the external supplier's V\&V capability can perform the assessment easily and efficiently since our questionnaire which is made of the specific $\mathrm{V} \& \mathrm{~V}$ tasks and its related artifacts makes the assessor easily understood its purposes and contents. Specially, a Korean company which provides the NPP related services begins applying our framework in the initial steps of acquisition process using the web-based assessment supporting tool. Our framework can be used as the criticalitybased $V \& V$ process improvement model by enforcing the compliance of minimum $\mathrm{V} \& \mathrm{~V}$ tasks of the target V\&V capability level. Consequently, through using our framework as a tool for the V\&V capability assessment and/or $\mathrm{V} \& \mathrm{~V}$ process improvement, the acquirers of safety-critical software project can expect the highquality safety-critical software by selecting the proper supplier and the internal/external suppliers can initiate the $\mathrm{V} \& \mathrm{~V}$ process improvement activities based on the assessment result. Finally, we plan to improve our framework by reflecting the feedback of the industry such as adjusting the granularity of each V\&V tasks after performing the several feasibility studies and the realistic analysis.

\section{References}

[1] N. Leveson, "Software Safety: Why, What, and How", ACM Computing Surveys, June, 1986, vol. 18.

[2] M. B. Chrissis, M. Konrad, and S. Shrum, CMMI: Guidelines for Process Integration and Product Improvement, Addison-Wesley, 2003.

[3] I. Burnstein, A. Homyen, T. Suwanassart, G. Saxena, and R. Grom, "A testing maturity model for software test process assessment and improvement", Software Quality Professional, 1999, vol. 1, pp8-21.

[4] IEEE Standards Board, IEEE Std. 1012-1998 - IEEE Standard for Software Verification and Validation, The Institute of Electrical and Electronics Engineers, Inc., 1998.

[5] IEEE Standards Board, IEEE Std. 7-4.3.2-1993 - IEEE Standard Criteria for Digital Computers in Safety Systems of Nuclear Power Generating Stations, The Institute of Electrical and Electronics Engineers, Inc., 1993.

[6] IEEE Standards Board, IEEE Std. 7-4.3.2-2003 - IEEE Standard Criteria for Digital Computers in Safety Systems of Nuclear Power Generating Stations, The Institute of Electrical and Electronics Engineers, Inc., 2003.

[7] IEEE Standards Board, IEEE Std. 1228-1994 - IEEE Standard for Software Safety Plans, The Institute of Electrical and Electronics Engineers, Inc., 2003.

[8] U.S Nuclear Regulatory Commission, Regulatory Guide 1.168 - Verification, Validation, Reviews, And Audits For Digital Computer Software Used in Safety Systems of Nuclear Power Plants, Office of Nuclear Regulatory Research., 1997.

[9] ISO, ISO 9001:2000 - Quality management systems - Requirements, ISO, 2000.

[10] CMMI in Small Settings Toolkit Repository from AMRDEC SED Pilot Sites; DRAFT 14, SEI, 2004.

[11] B. Mutafelija and H. Stromberg, Systematic Process Improvement Using ISO 9001:2000 and CMMI, Artech House, 2003.

[12] S. Masters and C. Bothwell, "Maturity questionnaire", Technical Report, SEI, 1994, CMU/SEI-94-SR-7.

[13] I. Burnstein, Practical Software Testing, Springer, 2003. 